\title{
Epidemiology of Pesticides in Developing Countries
}

\author{
Abdou Kh A ${ }^{1 *}$ and Hend M Abo El-Atta ${ }^{2}$ \\ ${ }^{1}$ Department of Forensic Medicine and Toxicology, Benisuef University, Egypt \\ 2Department of Forensic Medicine and clinical Toxicology, Mansoura University, \\ Egypt
}

\section{Review article \\ Volume 3 Issue 1}

Received Date: December 16, 2017

Published Date: February 23, 2018

*Corresponding author: Khaled Abbas Helmy Abdou, Department of Forensic Medicine and Toxicology, Faculty of Veterinary Medicine, Benisuef University, Egypt, Tel: 00201001906577; Email: drkahaa@bsu.edu

\section{Abstract}

Chemical pesticides are group of substances of different classes according to their target species (Eg. herbicides and insecticides), that are created for eradication and control of pests. A global trend of transition from agricultural to industrial workforces has been observed lately in developing countries to increase agricultural productivity which imply increased use of non-patented, more toxic, inexpensive, older, environmentally persistent pesticides to protect their plantations and increase their production up to two or three crops per year seeking for increasing their economic development. The world health organization declared that pesticides - related intoxications in developing countries, have the highest percentages of acute human in toxications either intentional suicidal or occupational exposures, as well chronic intoxications. This widely spread use of pesticides represents a major public health problem which has a real and potential adverse health impacts on human and animal lives, such as cancer. Many different international bodies have declared some preventive measures to reduce this problem such as properly developing a common philosophy of pertaining such chemicals and applying legislations for their use; farmer education, and establishment of personal and family protection programs. Lack of scientific evidence with defective large scale surveillance data to estimate the magnitude of the problem and the significant association between pesticide use and chronic adverse health effects in developing countries; requires close monitoring to identify the most hazardous pesticides to restrict or ban their use through conduction of well-designed epidemiological studies.

Keywords: Pesticides; Developing countries; Preventive measures

Abbreviations: FAO: Food and Agriculture Organization of the United Nations; WHO: World Health Organization.

\section{Introduction \& Epidemiology}

Pesticides is defined to be any substance or a mixture of substances that is used for prevention, destruction or controlling pests including vectors of either human or animal diseases; and unwanted plant or animal species that may interfere with the production, processing, storage or transport of food [1].

There are several classifications to pesticides classes. They may be classified according to their chemical structures and uses, for example, insecticides, herbicides, 
molluscicides, rodenticides, fungicides, nematocides, acaricides, miticides, avicides; They may also be classified according to their mechanisms of action; or their degree of toxicity and health hazards [2] (Table 1).

\begin{tabular}{|c|c|c|c|}
\hline \multicolumn{2}{|c|}{ WHO Pesticide Toxicity Classification } & \multicolumn{2}{c|}{ LD50 for the rat (mg/kg body weight) } \\
\hline WHO hazard classification & WHO class & Oral LD 50 & Dermal DD $_{50}$ \\
\hline Extremely hazardous & Ia & 5 or below & May-50 below \\
\hline Highly hazardous & Ib & $50-2000$ & $200-2000$ \\
\hline Moderately hazardous & II & Over 2000 & Over 2000 \\
\hline Slightly hazardous & III & \multicolumn{2}{|c|}{5000 or higher } \\
\hline $\begin{array}{c}\text { Unlikely to present acute } \\
\text { hazard }\end{array}$ & IV &
\end{tabular}

Table 1: WHO - recommended classification of pesticides hazard [2].

Pesticides have several mechanisms of action; they may target acetyl choline esterase enzymes, sodium channels, GABA receptor gated chloride channels, mitochondrial complex, glutamate- gated chloride channels, protein synthesis, glutamine synthetase and enolpyruvylshikimat3-phosphate synthetase enzymes; these mechanism provide different and a lot of widely distributed toxic pesticide compounds that are heavily used in the market [3].

In developing countries, the use of pesticides is about $20 \%$ of the total world consumption since 1980 and it has been increasing annually [4]. One of the main strategies to increase crop productivity for rapidly growing population is effective pest management, since more that $45 \%$ of annual food production is lost from pest infestation which can be more severe in certain tropical developing countries due to the prevailing high temperature and humidity that result in rapid multiplication of pests [5]. Hence, the extensive use of pesticides, in developing countries, is usually refers to the challenging need to use them in agriculture for pest control to ensure the sufficient production of food which is needed to face the growth rates of population in developing countries (Eg: Egypt)[6].

Another reason for this extensive usage is that pesticides are more valued by developing countries, especially those in tropical regions, seeking to enter the global economy by providing off-season fresh fruits and vegetables to countries in more temperate climates, hence, most of the developing countries are undergoing a transition from an agrarian culture to newly industrialized society searching for the economical prosperity leading to increased consumption of such chemicals in agriculture [7].
Since the green revolution, there was a shift from labor- to machine- intensive agricultural practices with intensive use of pesticides for the control of pests especially in developing countries; such chemicals are extremely dangerous and exposure to them can lead to environmental contamination with real potential adverse health effects [8]. Data on the worldwide pesticide sales showed that many of the banded withdrawn pesticide compounds (e.g. DDT, organ chlorine insecticides, organophosphate, carbamates, herbicides)are produced and targeted the markets of the developing countries (that exceeded US\$ 8.0 billions per year) through domestic companies, multinational subsidiaries or joint ventures [6].

It is estimated that around 800,000 people in developing countries may have died due to pesticides since the onset of the Green Revolution, and nearly 20,000 people die each year of pesticide consumption through their food due to application of hazardous chemical pesticides [8]. Around 1-5 million cases of pesticide poisoning are estimated annually among agricultural workers, most of them happens in developing countries [2]. In Africa, a number of Member States reported increased incident poisoning with hazardous pesticides in different regions countrywide, such as, in 2012, Kenya reported a total number of 1479 cases and 579 fatalities from pesticide poisoning, and Uganda reported about 87 fatalities from pesticides poisoning [2].

Studies from developing areas in Central America (El Salvador and Nicaragua) indicated an overall incidence rate of 35 per 100.000 for acute pesticide poisoning in the general population and 17.8 per 100.000 occupationallyrelated in Thailand. In Belize, it was estimated that 17 pesticide poisonings per 100.000 residents occur each year [9]. 
Romania as one of the developing countries estimated that their pesticides' use was approximately 8.000 tones (100\% A.S.). It was confronted to have public health problem by having inadequate safety and hygiene practice regarding applying, formulating, storing, transporting and manufacturing of pesticides [10].

India is predominantly an agricultural society, which manifests a significant transformation after independence, where increased agricultural production, use agro-chemicals, and improved irrigation facilities; had taken place. Despite that, increased incidence of pests and diseases was remarked. Thus, India started to develop the industry of pesticide production which comprised the largest industry in whole Asia; producing more than 125 basic producers of large and medium scale and more than 500 pesticide formulation; that results in the production of more than 90.000 metric tons of pesticides including very toxic compounds such as DDT, hexachlorocyclohexane, and pentachlorophenol which represent more than $40 \%$ of total pesticide consumption in India followed by organophosphate pesticides; thus the three major categories used in agriculture are, lindane, DDT, and malathion; they account for $70 \%$ of the total pesticide consumption in India [5].

The cumulative usage of hexachlorocyclohexane, in India, was about 575.000 tons by year 1985 and since then, about 45.000 tons has been used annually. Besides, it is considered the only country that applied more than 100.000 tons of DDT in its agricultural and malarial control programs until banned for use in 1989 [11].

The pattern of agrochemical-application in India for pesticide is not similar to that for the world in general, it shows skewed pattern toward insecticides which constitutes $76 \%$ of the whole pesticide against $44 \%$ globally; meanwhile, herbicides and fungicides' application is correspondingly less heavy $[8,12]$.

In Egypt, the irrigated lands for agriculture which represent only $5-7 \%$ of the total area are heavily contaminated with different pollutants, including the persistent organochroline that was delivered by the loaded River Nile with various types of pesticides and many other contaminants(especially toxaphene, aldicarb, parathion, methamidophos, alphacypermethrin, deltamethrin, and endosulfan) while crossing eight African counties from its origin African plateau till it reaches the Egyptian territory; as are all these African countries depend on such compounds for their cotton farming which is considered their principle crop; Besides the large amounts of commercial insecticides that had been injected into the environment during the last three decades; these chemicals were needed for the cotton crop which represents the main element for the national economy $[2,6]$.

Different studies revealed a great magnitude of human exposure to pesticides in Egypt, however official reports on pesticides poisoning are still lacking [6]. Abdelmegid and Salem surveyed 5913 patients admitted to the Alexandria Poison Center (APC). They found that pesticides poisoning constituted $14.3 \%$ [13]. It was higher in females $(16 \%)$ than in males $(13 \%)$, and predominated among the group of 15-25 years during the year 1994.

\section{Risk Factors}

Different risk factors have been declared that increase toxicity of pesticides especially in developing countries including: lack of pesticide registration scheme; importing highly toxic banded pesticides; no national plan for monitoring pesticide residue; lack of safeguards and poisoning surveillance systems; misuse and improper handling of pesticides; ignoring of re-entry and pre harvest intervals; involvement of children and women in farm work; illiteracy regarding the basis of Good Agriculture Practice; excess use of household pesticides; malnutrition; infectious and parasitic diseases; multiple exposure to toxic chemicals; and poverty [6]. These risk factors could either increase the like hood of higher exposure to pesticides, or increases the toxic effects from that exposure on human body.

As well, a number of developing countries tend to manufacture older, non-patented, least expensive, more acutely toxic and environmentally persistent agents that had been banned worldwide; or to formulate them from imported active ingredients, due to limited access of such developing countries to foreign currency [7].

\section{Manner of Poisoning \& Health Consequences}

Pesticide poisoning has been recorded to occur suicidal, homicidal, or accidental [14]. Accidental poisoning occurs most frequently among agricultural workers or those who live adjacent to heavily treated agriculture land; especially in developing countries; such mode occurs frequently due to lack of attention to safety precautions, poor spraying techniques, laxity of safekeeping of the chemicals, carless disposal of empty pesticides containers, consumption of food and beverages while working, lack of personal hygiene, weakness of occupational legislation, and inadequate personal protection during their use [5]. 
In Africa, surveys indicate that a small number of farmers consistently use appropriate personal equipment due to cost and hot humid climate that make wearing such equipment uncomfortable; as well, accidental ingestion of contaminated crops is a major source of accidental poisoning as reported in Uganda, Gabon, Senegal and Benin $[15,16]$. This usually accounts to accumulation of obsolete pesticides in air, soil, water and food sources.

According to FAO, the key reasons for pesticides accumulation are :(1) increased their use to control outbreaks of locusts, mosquitoes, tsetse fly and pests; (2) product ban; (3)poor storage and stock management; (4) lack of coordination among donor agencies; (5) commercial interests of the private sector. This eventually results in pesticides' leaching into echo systems [17].

Exposure to pesticides can be through different routes of exposure such as inhalation, ingestion and dermal contact; that occurs either occupational or nonoccupational situations5. Occupational exposure may occur through harvesting tasks that may require direct contact with such agents; while, non-occupational pathways may manifest due to direct environmental exposures from heavily contaminated air, water, and soil; or through dietary pathways [18]. There have been four large groups of population of potential high risk of exposure to pesticide hazards: (1) farm workforce (2) laborers in pesticides factories; (3) people live in areas with intensive pesticide use or production (especially children and sick individuals); (4) people exposed to persistent pesticides accumulated in food (such as habitual consumers of fish; livestock, and dairy products) [14].

Pesticides toxicity can be due to acute or chronic exposure, according to the size of population exposed, where the largest sector of the population is chronically exposed to pesticides through long term exposure at low dose levels, whereas smaller segments of population are exposed acutely at high levels [4].

Acute exposure is a major health problem worldwide especially in developing countries, however, no reliable estimates to total number of population suffering from pesticides-related health effects [9]. In 1990, a World Health Organization/United Nations Environmental Programme (WHO/UNEP) declared that unintentional acute poisoning exceed 1 million cases each year, out of which 20.000 are fatal. Additionally, there are about 2 million intentional cases (mainly suicidal attempts) resulting in 200.000 deaths per year. The vast majority of those cases occur in developing countries [19].
Several survey studies were conducted in Thailand, Taiwan, Costa Rica and Nicaragua, all studies declared that the majority of acute intoxications either accidental or intentional can be attributed to pesticides intoxications [7]. The most likely explanation for the high numbers of suicidal cases in developing countries is the high case fatality associated with pesticide ingestion compared to the relatively low case fatality of many substances commonly taken in cases of self-poisoning in developed countries [20].

Although most of collected data was sparse, Gunnell, et al. [20] stated approximate estimates for percentages of suicidal attempts due to pesticide toxicity in six WHO regions around the world including developing countries: In Africa, Data on the African continent suicide due to pesticides, estimated the proportion and number of suicides about $22.9 \%$ and 7,800 (range from 5,200 to 21,910 ). Epidemiological surveillance data in countries of Central America (Belize, Costa Rica, El Salvador, etc.) indicates that pesticides account for $31 \%$ of suicides in this region. For South America (Brazil), they account for approximately $6.9 \%$ of all suicides. WHO estimates pesticide suicidal data in Eastern Mediterranean countries about $16.5 \%$ and 5,629 , based on confidence intervals around data for Jordan and Pakistan (countries comprising $31 \%$ of the population of the region), the plausible range for this estimate is 4,501 to 7,022.Estimates in South East Asia for the proportion and annual total of pesticide suicides in this region are $20.7 \%$ and 51,050 , with a range of 47,720 to 82,680 . This estimate is based on data from countries (India, Bangladesh, Sri Lanka and Thailand) who comprising $71 \%$ of the population of that region.

Health risk factors of pesticides depend on the hazardous compounds, how many people were exposed, what their risk -related demographic and socioeconomic and health profile [6]. Chronic exposure to pesticide had been linked to many hazardous effects on humans. Carcinogenesis is one of the most serious toxic effects of chronic exposure to such compounds. It had been linked with the development of hematopoietic cancers such as non Hodgkin lymphoma and leukemia, and cancers of the prostate, pancreases, liver, and many other body systems $[21,22]$.

Breast cancer was questioned to be associated with high body burdens of several compounds such as DDT, and DDE, however, this association was not approved yet [23]. This can be initiated through different mechanisms which include cytotoxicity with sustained cell proliferation, inhibition of apoptosis, oxidative stress, activation of cellular receptors and inhibition of 


\section{Advances in Clinical Toxicology}

intracellular communications; as well, pesticides may act as promoters through immune suppression [24].

Neurotoxicity is well established health consequence to chronic exposure to pesticides; such as chronic induced neuropsychiatric disorders Parkinson's disease and different neurodegenerative disorders [25].

Another health consequence to chronic pesticide exposure is the reproductive toxicity that may begin with parental exposure to such chemicals. Preconception, conception, prenatal, and postnatal periods are considered all vulnerable risk stages for adverse reproductive outcomes following exposure to pesticides such as genetic and hormonal toxicity and miscarriages [26]. A study was conducted by Amr who studied the impact of exposure to pesticide on the health status of workers engaged with Egyptian plants contaminated with pesticides [27]. It was found that dermatitis and neuropsychiatric manifestations were the most prevalent health effects in exposed groups, besides, gastrointestinal, genitourinary and ocular manifestations as well as hepatomegaly, polyneuropathy and sensory hypothesia; were associated with chronic exposure to pesticides.

Several studies stated the toxic effects on animals due to exposure to pesticide compounds. They all have clearly potential to cause reproductive toxicity such as birth defects [28]. Immunotoxicity and endocrinal disruption are other consequences that have been proved to pose growing threats to human and wildlife health [29]. Delayed neurotoxicity to farm animals is one of the proposed impacts on animal health [6].

The global economic burden of suicide and premature mortality, considered deaths from pesticide ingestion is major contributor factor which increased by the indirect health care effects following suicidal cases using pesticides: first: poisoned cases often requires intensive care, in particular ventilation; in a study that was conducted in general hospital in Sri Lanka in 1995-6, it was found that $41 \%$ of bed occupancy on medical intensive care beds was for the treatment of pesticide poisoning [30]. This not only drains limited healthcare budgets but also prevents the treatment of other patients requiring intensive care. Furthermore, the second burden is the loss of young, economically active, community members through premature death that may influence productivity in their communities [31]. Therefore, a balance should be adjusted between the costs of self-harm and agricultural benefits, and to be integrated in pest management incorporate the possibility of replacing pesticides which are toxic to humans with less toxic, but equally effective alternatives as bio-pesticides.

\section{Environmental Consequences}

Pest resistance, either physiologically or behaviorally; and destruction of natural pest enemies are considered one of the most serious impacts that may affect the environment and ecosystems; besides plants and animals ranging from beneficial soil microorganisms and insects, non-target plants, fish, birds, and other wildlife. This can be seen widely in developing countries; hence, such resistance may result in rising pest species; besides, agricultural losses resulting from reduction of insect pollination of crops and eco-contamination with pesticides which may hinder farmers to rotate their crops [32].

Echo toxicity, in which pesticides may enter the environment through air (e.g. aerial spraying), water (e.g. direct treatment of irrigation channels), and food (e.g. direct application of pesticides to a crop or farm animal). This creates a state of pesticides persistence in the environment, which may have long detrimental effects if more hazardous and less degraded compounds were used, a feature which is characteristic in developing countries[33]. The typical pesticides detected in crops, water, and soil are the organochlorines and their degraded products; for examples, samples collected from four African cotton production sites revealed that more than $77 \%$ of samples contain DDT, endosulfan I, II , endosulfan sulfate, and profenofos; as well food samples in Ghana $[34,35]$.

Such toxic pesticides disturb the soil conditions and destroy the health pool of bio-control agents that normally co-exist with vegetation; which are considered agricultural friendly that need to be nurtured, cared and developed by reducing the reliance on such chemicals in agriculture [5].

\section{Preventive Measures \& Regulations}

Bio-pesticides are typically microbial biological pest control agents that simulate chemical pesticides. Most of these agents have no detected harmful residues; cheaper when locally produced, more effective in the long-term, and biodegradable. Currently in 2013, there were approximately 400 registered bio-pesticide active ingredients and over 1250 actively registered biopesticide products by U.S. Environmental Protection agency [8].

Several developing countries seek to control their uses of pesticides to minimize the deleterious health hazards to their population. In Egypt the use of pesticides was governed by Act No. 53 of 1996 for agricultural pesticides 


\section{Advances in Clinical Toxicology}

that was issued by the Minister of Agriculture, and Act No. 127 of 1955 for house hold pesticides that was issued by the Minister of Health; this Act agreed with FAO guidelines on registration and controlling pesticides; with subsequent amendments that were added according to the need [6].

India has also established a comprehensive statute for pesticide regulations regarding their import, manufacture, sale, transport and use (Insecticide Act 1968, and Insecticides rules, 1971); that ensure quality, safe and efficacious use of pesticides in farming community and pesticide industry; and to restrict and ban the use of any hazardous products. Besides, a network of 46 pesticides testing laboratories, which perform an annual analysis capacity of over 55.666 samples of pesticides for continuous monitoring of the quality of pesticides, and four poison information centers to ascertain the prevalence of pesticide residues; had been established as well [5].

In Romania, legislation was established by 1995 (Environmental Protection Law 137/1995), however, this legal frame was having gaps and non-concordances [10]. Since it is mandatory to determine the magnitude of the problem through precise estimates and identification of cases and deaths resulting from acute pesticides poisoning taking into account several challenges such as: misdiagnosis by health-care providers, lack of readily accessible health care in rural populations, exclusion of non-hospitalized cases, resigned acceptance by workers that adverse health effects are expected, and the fact that less severe cases of acute poisoning may not seek health care; and further, many developing countries lack the resources to establish and maintain the necessary surveillance programs and to obtain confirmatory laboratory testing for all possible cases of acute poisoning. Therefore, a standard definition and classification scheme for acute pesticide poisoning to enable its identification and diagnosis, especially at rural clinics and primary health-care systems; was established [9]. Although such scheme enables only assessment of acute poisoning and provides a framework for further epidemiological studies, it does not allow for the assessment of chronic poisoning.

The World Health Organization has set a gap analysis for the African situation regarding the management of chemicals of the public health concern in means of strengths and challenges toward such chemicals; their sources of exposure; legislations and policy; human resource, surveillance, and laboratory capacity; and management of chemical waste and stockpiles [2].

\section{Recommendations}

Hence, several recommendation measures had been suggested to over-come such challenges as: developing standard operating procedures and comprehensive policies for an integrated approach to chemical management, for limiting occupational and environmental exposure; establishing national multisectoral task forces that deal public health and environment related issues concerning such chemicals; conducting surveillance for potentially exposed groups to chemical exposure especially the most vulnerable such as children and pregnant women; establishing regional reference laboratories and new poisons centers for management of chemicals of public health concern [2].

Previous research has demonstrated that occupational non- intentional causes vary from $10 \%$ to $50 \%$ in developing countries, which seemed of unclear etiology, but mostly related to inconsistent recording methodology and lack of standard case definition for acute pesticide poisoning. These variations may result in underestimation of the true incidence of acute pesticide poisoning [9]. Close monitoring of the reported cases of acute and chronic intoxications through hospital records that permits the identification of the most hazardous agents; and have steps should be taken to restrict or ban their usage.

Regional and national scientific epidemiological studies for investigation and clarification of the extent of the problem, should be conducted within a collaborative action plans with paid attention for high risk groups such as children, farm workforce and occupational workers; because their exposure can be higher the general population; that can prove the association between pesticide exposure and health hazards.

Since few governments in developing countries had a definite philosophy for pertaining such chemicals and importing them whenever is needed [2], strict legislation and regulations' policies are mandatory to be applied; besides those countries should subscribe to international programs on chemical safety?

\section{References}

1. Hamilton D, Crossley S (2004) Introduction. In: Hamilton D, et al. [Eds.], Pesticide Residues in Food and Drinking Water: Human Exposure and Risks. John Wiley \& Sons, England, pp: 1-25. 


\section{Advances in Clinical Toxicology}

2. WHO (World Health Organization) (2014) Chemicals of public health concern in the African Region and their management, Regional Assessment Report.

3. Costa LG (2008) Toxic effects of pesticides. In: Klaassen CD, (Eds.), Toxicology: The Basic Science of Poisons. Casarett, McGraw-Hill, USA, pp: 883-930.

4. Koh D, Jeyaratnam J (1996) Pesticides hazards in developing countries. Sci Total Environ 188(1): 7885.

5. Abhilash PC, Singh N (2009) Pesticide use and application: An Indian scenario. J Hazard Mater 165(1-3): 1-12.

6. Mansour SA (2004) Pesticide exposure-Egyptian scene. Toxicology 198(1-3): 91-115.

7. Ecobichon DJ (2001) Pesticide use in developing countries. Toxicology 160 (1-3): 27-33

8. Bhardwaj T, Sharma JP (2013) Impact of Pesticides Application in Agricultural Industry: An Indian Scenario. International Journal of Agriculture and Food Science Technology 4(8): 817-822

9. Thundiyil JG, StoberJ, Besbelli N, Pronczukd J (2008) Acute pesticide poisoning: a proposed classification tool. Bulletin of the World Health Organization 86(3): 161-240.

10. Vasilescu M (1998) Overview of pesticides in Romania.

11. Gupta PK (2004) Pesticide exposure-Indian scene. Toxicol 198(1-3): 83-90.

12. Vijgen J, Bhilash PC, Forter M, Torres J, Singh N, et al. (2011) HCH isomers as new Stockholm Convention POPs - A global perspectives on the management of Lindane and its waste isomers. Environ Sci Pollut Res Int 18(2): 152-162.

13. Abdelmegid LAM, Salem EM (1996) Trends in the pattern of acute poisoning in Alexandria Poison Center in 1994. In: Dev (Eds.), Proceedings of the 3rd Congress on Toxicol. Countries, Cairo, Egypt pp: 237 250.

14. Costa LG (2013) Toxic Effects of Pesticides. In: Klaassen CD (Eds.), Toxicology: The Basic Science of Poisons McGraw Hill, New York, pp: 934-980.

15. Nweke OC, Sanders WH (2009) Modern environmental health hazards: a public health issue of increasing significance in Africa. Environ Health Perspect 117(6): 863-870.

16. Lu C, Fenske RA, Simcox NJ, Kalman D (2000) Pesticide exposure of children in an agricultural community: evidence of household proximity to farmland and take home exposure pathways. Environ Res 84(3): 290-302.

17. FAO (Food and Agriculture Organization of the United Nations) (2012) The State of Food Insecurity in the World Economic growth is necessary but not sufficient to accelerate reduction of hunger and malnutrition.

18. Ghimire N, Woodward RT (2013) Under-and over-use of pesticides: An international analysis. Ecological Economics 89: 73-81.

19. Bertolote JM, Fleischmann A, Butchart A, Besbelli N (2006) Suicide, suicide attempts and pesticides: a major hidden public health problem. Bull World Health Organ 84(4): 260.

20. Gunnell D, Eddleston M, Phillips MR, Konradsen F (2007) The global distribution of fatal pesticide selfpoisoning: Systematic review. BMC Public Health 7(357): 1-15.

21. Merhi M, RaynalH, Cahuzac E, Vinson F, Cravedi JP, et al. (2007)Occupational exposure to pesticides and risk of hematopoietic cancers: meta-analysis of casecontrol studies. Cancer Causes Control 18(10): 12091226.

22. Charlier CJ, Dejardin MC (2007) Increased risk of relapse after breast cancer with exposure to organochlorine pollutants. Bull Environ Contam Toxicol 78(1): 1-4.

23. Holland MG (2006) Insecticides: organic chlorines, pyrethrins/ pyrethroids, and DEET. In: Flomenbaum NE (Eds.), Goldfrank's Toxicologic Emergencies, McGraw-Hill, USA, pp: 1524-1535.

24. Irigaray P, Newby JA, Clapp R, Hardell L, Howard V, et al. (2007) Lifestyle-related factors and environmental agents causing cancer: An overview. Biomed Pharmacother 61(10): 640-658.

25. ElbazA, ClavelJ, RathouzPJ ,Moisan F, Galanaud JP, et al. (2009) Professional exposure to pesticides and parkinson disease. Ann Neurol 66(4): 494-504.

26. Perry MJ (2008) Effects of environmental and occupational pesticide exposure on human sperm: A 
systematic review. Hum Reprod Update 14(3): 233242.

27. Amr MM (1990) Health Hazards of Pesticides. Project of Pesticide Intoxication-Egypt, Final Report. Faculty of Medicine, Cairo University, Egypt, International Development Research Centre (IDRC), Canada.

28. Weselak M, Arbuckle TE, Wigle DT, Walker MC, Krewski D (2008) Pre-and post-conception pesticide exposure and the risk of birth defects in an Ontario farm population. Reprod Toxicol 25(4): 472-480.

29. McKinlay R, Plant JA, Bell JNB, Voulvoulis N (2008) Endocrine disrupting pesticides: Implications for risk assessment. Environ Int 34(2): 168-183.

30. Gunnell D, Eddleston M (2003) Suicide by intentional ingestion of pesticides: a continuing tragedy in developing countries. Int J Epidemiol 32(6): 902-909.

31. Eddleston M, Sheriff MH, Hawton K (1998) Deliberate self-harm in Sri Lanka: an overlooked tragedy in the developing world. BMJ 317(7151): 133-135.
32. Mansour SA (2008) Environmental impact of pesticides in Egypt. In: Whitacre DM (Eds.), Reviews of Environmental Contamination and Toxicology. Springer Science and Business Media LLC New York, USA 196: 1-51.

33. Koren H, Bisesi MS (2003) Pesticides. In: Handbook of Enviromental Health, Biological, Chemical and Physical Agents of Environmentally Related Disease, CRC Press LLC, USA pp: 347-386.

34. Dem SB, Cobb JM, Mullins DE (2007) Pesticide Residues in Soil and Water from Four Cotton Growing Areas of Mali, West Africa. J Agric Food Environ Sci 1: 1-12.

35. Ntow WJ, Tagoe LM, Drechsel P, Kelderman P, Gijzen HJ, et al. (2008) Accumulation of persistent organochlorine contaminants in milk and serum of farmers from Ghana. Environ Res 106 (1): 17-26. 